\title{
Analysis of the Impact of 5G Development on the Macroeconomy
}

\author{
Michael Fahn and Shiming Yan
}

\author{
Buchholz High School, Gainesville, FL 32606, USA, Email: michaelfahn2004@ gmail.com \\ The Second High School Attached to Beijing Normal University, Beijing, 100088, China, \\ Email: Owenyan20031121@gmail.com
}

\begin{abstract}
Modern mobile communication is remarkable journey for human to conquer. From $1 \mathrm{G}$ to $5 \mathrm{G}$, humans always attempt to break the limit and to discover the future of technology. The fifth generation promotes the living standard and alleviates poverty in the rural areas, which brings convenience and wealth to people. 5G makes upgradation for autonomous car, especially when it analyses complicated traffic status. IoT is the connection for components in the factories, robotics even homes. $5 \mathrm{G}$ provides it with better performance and more efficient algorithm. AI must be a intriguing technique which is popular in nowadays innovation industries. $5 \mathrm{G}$ enables it to be much "humanized" and advanced in the future. $5 \mathrm{G}$ is the thing which could find the inner strength of techniques. There will be a bright potential for mobile communication in the future.
\end{abstract}

Keywords: 5G, labour market, GDP, international trade, living standard

\section{INTRODUCTION}

Imagine this: you just wake up in the morning and your phone is telling you about the weather outside your house. You might eat something greasy food last night, so your phone tells you to drink more water and eat salad this morning. The light is consonance with your need of turning up the light and opening the curtain. It's time for breakfast, but the food isn't going cooked by yourself. Your kitchen becomes your chief and arranges your diet healthily. Some news about the world? The television is turned on automatically by itself and turn to $\mathrm{CNN}$ or BBC. In your garage, the car already filled the tank and notify you about today's traffic ${ }^{[1]}$. Everything looks harmonious and highly teched. This is your life when $5 \mathrm{G}$ is updated. $5 \mathrm{G}$ would be a game changer in nowadays society. There will be more convenience in our daily life. The fifth-generation network of communications for cellular mobile devices, known as $5 \mathrm{G}$, is one of the more recent technological developments that could shape the world. Premiered in 2019, its usage of more cutting-edge technologies allows it to operate a higher speed than its predecessor $4 \mathrm{G}$, and as such, it is set to replace $4 \mathrm{G}$. Across the range of $100 \mathrm{Mbit} / \mathrm{s}$ and 2Gbit/s, 5G uses three main groups of frequencies. The first is known as "lowband," and similar to $4 \mathrm{G}$, it uses low frequencies that have long ranges and slower speed than other forms of $5 \mathrm{G}$ such that it's not even significantly faster than LTE. ${ }^{[2]}$ The second is known as "midband," and although it is much faster than LTE, its higher frequencies produce a shorter range than lowband 5G. ${ }^{[2]}$ The third is known as "mmWave," and its frequencies are so high that its range doesn't allow you to even get service inside buildings at the cost of its speed.We are still at the advent stage of $5 \mathrm{G}$, but for many, it's safe to say that its far-reaching effects will extend into one surprising area: economics.

\section{DEVELOPMENT OF $5 G$}

When Alexander Bell first introduced telephone to this innocent world in 1876, human had entered a era of modern communication which made cavemen jealous who started inscribing on the caves. The equipment which people used in the old days turn into wireless and pre-cellular which could be pioneering in 19 century. As better technology devoted to this industry, 0 generation of modern mobile communication technology, known as OG, had launched in 1940s. We started to see picture of people who was taking huge phone besides their ears, which looks unconformable nowadays. In 1979, there was a striking news in Tokyo that $1 \mathrm{G}$ had been invented. Nippon Telegraph was the first company made $1 \mathrm{G}$ commercialized. There were two ways of signal: 
digital signal and via analog. ${ }^{[3]} 1 \mathrm{G}$ used via analog to generate, but only used for voice call which had 2.4 kbps for speed and feeble connection between caller and listener. Finland, in 1991, used digital signal to create GSM for $2 \mathrm{G}$. The service had faster speed which could be $14.4 \mathrm{kbps}$ and $900 \mathrm{MHz}$ for range. In addition, SMS was started to be available during $2 \mathrm{G}$. GPRS, $2.5 \mathrm{G}$, can supported IP to connect to internet which has 53.6kbps. AT\&T launched $2.75 \mathrm{G}$ by using EDGE which has $236.8 \mathrm{kbps}$ for surfing. Near the millennium, technology started to have a dramatic further jump. 3G had been launched by South Korea in 2001 by SK Telecom which was the first commercial $3 \mathrm{G}$ in the world. It has $384 \mathrm{kbps}$ for moving device and $2 \mathrm{mbps}$ for non-moving device. The general public finally could watch video online though it wasn't so limpid as 1080 p as now. 3G has other derivative. HSPA+ offers $3 \mathrm{G}$ a faster speed which could reach $22 \mathrm{mbps}$. Currently, we are using $4 \mathrm{G}$, a generation of wireless telecommunication which has larger range of bands and faster speed for connections, in out daily life. There are many technology can't live without 4G: mobile web, HD video player, cloud storage, self-driving car, 3D even TV. The generations of telecommunication made the world more interrelated. Inevitably, $5 \mathrm{G}$ will be a game changer in the history of human communication history.

However, some problems occur in recent $5 \mathrm{G}$ situation. One of the main problems with developing $5 \mathrm{G}$ is the infrastructure needed: while $4 \mathrm{G}$ networks used low-frequency long-range waves, 5G use high-frequency short-range waves, necessitating many more antennas/towers. Some carriers are trying to combine the two types of technology for the two generations of network communications to create a multi-wave framework, and as networking power from more antennas increases, speed and capacity will rise. The carriers that are ahead in the game have already begun to take their $5 \mathrm{G}$ development outside of the lab, such as Fujitsu and Samsung at the University of Surrey in the United Kingdom who are playing around with different implementation methods to get their desired speeds. Although many such corporations/entities are vying for control over their/others' 5G technology, many are questioning if all this development will be made available or will yield results to consumers. By 2021, there will be at least 150 million active 5G subscriptions worldwide and a large-scale availability means not only increased connection speed, but multi-device support. These developments will surely take mobile networks and modern communications to the next level.

\section{IMPACT ANALYSIS}

\subsection{Labour market}

One of the largest impacts that 5G will have economically is on employment. A simple entertaining of various scenarios can give an overview of what's to come: the replacement of repairmen when AR headsets give live guided instructions or low product inventories automatically triggering replacement orders without an action from any employee. With or without new employees due to $5 \mathrm{G}$, the vast majority of businesses of all-sizes say that they expect to see productivity gains: $88 \%$ of small and midsized enterprises, $91 \%$ of U.S. organizations, $90 \%$ of Asian organizations, and $85 \%$ of European organizations to be exact.

One specific way in which $5 \mathrm{G}$ will surely take its toll on employment is its improvement of remote work.Participation in the customarily optional remote work usually entails that the employee have consistent access to high-speed Internet, relegating workers to suffocating home offices and similar spaces. The speed and reliability that $5 \mathrm{G}$ offers will allow employees to finally be able to work not only away from the office, but away from the nearly-equally-confining home offices. Service and blue-collar workers will also be able to remotely work when inspection and monitoring can be done through live video feeds and doctors can do likewise with implants and wearable devices, all undergirded by a reliable and fast $5 \mathrm{G}$ connection. When the lag and connection drop-offs end with 5G, videoconferences and remote work can eliminate the need for large physical office spaces and lower the operating cost for businesses, opening up room for the employment of more employees in this regard. Other effects of remote work on employment include those on job-search, job training, VR and AR, and actual job loss/creation. With regards to job search, Eric Hanson, VP of market intelligence at Fuze says in TechRadar.com that "organizations can how look to hire the best worker-regardless of where they are based-instead of the worker that is based in their headquarters' city or trying to drive top talent towards urban areas." Furthermore, VR and AR can now be used under the enhanced $5 \mathrm{G}$ connection to simulate important scenarios that workers will face such as utility work and store robberies that require realistic simulation rather than bland explanation to properly train prospective employees.

As the experience under $5 \mathrm{G}$ becomes smoother and more effective, their adoption will finally see better numbers, especially as costs are driven down. Obviously, this same technology will help with remote training and the previously mentioned live and instant repair instructions prevalent in the manufacturing/factory-based industries.

Finally, job loss and creation are both inevitable with the development of 5G. IHS Markit tells us that by 2035, 22 million jobs (including spillover effects) will be created worldwide as a result of the onset of $5 \mathrm{G}$, although others will be eliminated. Talk of automation usually turns heads toward service and manufacturing 
positions, but many new occupations are liable to be majorly affected by $5 \mathrm{G}$. For one, every single person that drives to put food on the table including truckers, bus drivers, and taxi drivers could be quickly driven out (no pun intended) by self-driving vehicles finally possible, adoptable, and scalable under $5 \mathrm{G}^{[4]}$.

New skills in new industries that don't yet exist will pop up as a result of $5 \mathrm{G}$ as evidenced by the new training offered by cutting-edge companies like Amazon, and those who found themselves unemployed because of this very same technology will need to receive potentially extensive re-training/re-education to get back into the labor force.

Lastly with regards to employment, 8 individual sectors will be the most affected, and it's worth quickly reviewing them (selectively for time-related reasons). According to the Progressive Policy Institute, the sectors broadly categorized as agriculture, construction, utilities, manufacturing, transportation and warehousing, educational services, healthcare and social assistance, and government will see 43, 228, 14, 309, 157, 299, 706, and 290 thousand jobs directly created in their respective industries in that order in the short-term.

In agriculture, the country still massively relies on low-cost labor, and with a rapidly changing environment, temperatures, and precipitation levels, "precision agriculture will rely on an interconnected system of low power sensors, integrated equipment, and data - all powered by $5 \mathrm{G}$ - to monitor field conditions and maximize yields while efficiently allocating scarce resources such as water." In construction, digitization becomes increasingly important as high costs and low productivity remain pertinent issues within this industry. The Bureau of Economic Analysis tells us that while the cost of construction has risen $118 \%$ since 2000, prices in the economy have "only risen $41 \%$ over the same time span." 5G "communication grids" can make automated equipment integrate in a more flexible and seamless way, and the same goes for skilled workers. This new technology also allows for more precise calculations and applications that reduce perilous errors, and as costs are reduced, demand will rise, and construction will finally become more efficient and cheaper.

Finally, a look at the traditionally automation-wary sector of manufacturing tells us what we pretty much already know: high costs and low productivity will be remedied by $5 \mathrm{G}$-enabled information technology will yield new business models, access to new markets, better competition, meaning more jobs, more digitization, and the revival of jobs in low-density former industrial centers in the Midwest.

\subsection{Gross Domestic Product}

Furthermore, a standard approach to looking at economic effects of anything usually requires some sort of mention about gross domestic product (GDP). Nokia's 5G economic forecast estimates that global GDP will increase by $\$ 8$ trillion by 2030 fueled by a $\$ 4.5$ trillion investment in technologies necessary to support such growth. ${ }^{[4]}$ One important pattern that Nokia looks at is the investment of industries in "information and communications technology" known as ICT. ${ }^{[4]}$ While 5G technology only represents a miniscule proportion of total current ICT spending, it will represent a majority within 7 years, and by $2030, \$ 4.5$ trillion of a total of $\$ 6$ trillion in ICT spending will be spent on $5 \mathrm{G}$ technologies according to Telecompetitor. ${ }^{[4]}$ It's no surprise that current digital industries are the ones that dominate ICT spending (70\% with only $25 \%$ of the workforce and $30 \%$ of GDP contribution, again according to Nokia), and with physical industries that look towards digitization like manufacturing, healthcare, transportation, retail, education, and utilities, an overall $6.5 \%$ annual increase in ICT spending is forecasted. ${ }^{[4]}$ Companies that focus their energy on ICT and 5G-related spending will be the ones that grow the fastest in the upcoming years and decades, and they will be the largest reason for the $\$ 8$ trillion next-decade increase in global GDP.

\subsection{International Trade}

Finally, the development of $5 \mathrm{G}$ by companies of different nations has become a key issue in recent economic times. According to the Defense Innovation Board, "the leader of $5 \mathrm{G}$ stands to gain hundreds of billions of dollars in revenue over the next decade, with widespread job creation across the wireless technology sector" as described earlier in this paper. With this pressing economic incentive, the US government has turned its attention to its largest competitor in the $5 \mathrm{G}$ race: China. The Chinese government has invested enormous amounts of money into companies to develop $5 \mathrm{G}$ and such companies hold the majority of the world's $5 \mathrm{G}$ patents. Seeing as most of these companies are funded by, partly regulated/controlled by, and have ties to the Chinese government, the US government under President Donald Trump deems some of these companies like Huawei to be potential national security threats as their technology could be weaponized for espionage or as threats of "critical communication network" shutdowns during future international conflicts.

President Trump and the US intelligence community have concluded that on that basis and because of, according to the Council on Foreign Relations, the Chinese government's willingness to rely on "intellectual property theft, forced technology transfers, cyberespionage and discriminatory treatment of foreign investment," tariffs must be implemented on imported Chinese goods and companies like Huawei must be barred from US markets in order to get China to 
negotiate for better terms that perhaps favor the US in this $5 \mathrm{G}$ race. Though some like Scott Kennedy, deputy director of the Freeman Chair in Chinese Studies at the Center for Strategic and International Studies, think that Trump's approach diminishes the US's position on the importance of national security by making it negotiable at the cost of economic power, Trump plows ahead in his trade war and is hellbent on securing the US as the dominant world player as it relates to $5 \mathrm{G}$.

\subsection{Living Standard}

Poverty alleviation could be a stimulation for enhancing living standard. The year 2020 is crucial for China to achieve the goal of eliminating absolute poverty. However, COVID-19 became a obstacle for poverty alleviation. Digital technology enables online industry to flourish. Chongqing, a municipality in southwest China, has invested heavily in the construction of new infrastructure including $5 \mathrm{G}$ network, data center, AI and industrial Internet. In the central province of Henan, where 5.82 million rural people moved out of poverty from 2013 to 2019, modern information technology is helping create a favorable environment for businesses. The industry provides employment to many poor people. According to Zhu 2020, 5G have created directly 3 million jobs by 2020. In order to raise living standard, Chinses investment for $5 \mathrm{G}$ hits 3.5 trillion yuan and new information consumption services valued at over 8.3 trillion yuan. The 5G-fueled services will include high-definition video and virtual reality services which could be major communication during the lockdown period. For autonomous car technology to be unlocked, many experts agree that large-scale adoption of $5 \mathrm{G}$ - the next-generation wireless technology-is required. The current $4 \mathrm{G}$ network is fast enough to online stream full HD content and play online games, but it can't support safer and smarter autonomous cars. Transition of message between cars and their sensors are important to autonomous cars. Decisions have to be made in just two milliseconds, which need advanced mobile communication technology to support. Thanks to mobile edge computing, these functions are already realized today, based on LTE at a transmission rate of up to 300 megabit per second and latencies of less than 100 milliseconds, even in emergencies or remote-controlled driving at low speeds. $5 \mathrm{G}$ will offer even higher quality for many digital in-car services in the future. Transportation won't be complicated in the future. The only thing people need to do in the autonomous car is monitoring the route. There are no need for handling the wheel or pressing the accelerator. Exactly, we need 5G network badly and $5 \mathrm{G}$ is the thing we ask for.

IoT, known as Internet of Things, becomes a trend in nowadays families. The amenity, people feel when they come back to home in a scorching day, is created by air conditioner $^{[5]}$. Moreover, if people turn on their air conditioner in home, it'll take them longer time to cool off. IoT makes things connected to each other which bring significant convenience to people. This service started by using $4 \mathrm{G}$ network, but $4 \mathrm{G}$ couldn't afford the speed that IoT required. The primary attributes of $5 \mathrm{G}$ include significantly faster data throughput; support for massive machine-type communications in which large numbers of machines or devices communicate without any human interaction or control; and ultra-reliable, low-latency communication, says Bill Menezes, senior principal analyst at research firm Gartner. Massive IoT can support up denser sensors in one area. Not only families can use IoT to control their air conditioners or $\mathrm{TV}$, but also in some industries like robot or manufactory use $5 \mathrm{G}$ to promote better performance for their IoT. By using IoT, machines may know each other and make products more efficiently. IoT is a connection to each components like bridges which seamlessly link.

The majority just fell in love with the Terminator when it launched in the cinema. Every time you wake up your Siri for helping you to do something when you are hands full. AI is a mechanism which motivates machine to think independently. Since Turing test was created in 20th century, AI have been advanced and evolved. We can't be guaranteed that AI machine will replace human in the future, but the trend stays where it is. $5 \mathrm{G}$ would be a epinephrine for $\mathrm{AI}$ development which already shows promising future. Edge computing is a critical component of AI. Although edge computing, a technique which processes and analyses data in the application, has significant potential in the future, the reality hasn't shown the bright side yet. $5 \mathrm{G}$ can assist and accelerate AI by enhancing the speed and integration of other technologies, which speeds up the services on the cloud. Between now and 2025, the networking industry will invest about $\$ 1$ trillion worldwide on $5 \mathrm{G}$, supporting rapid global adoption of mobile, edge, and embedded devices in practically every sphere of our lives. As we can see the tendency of 5G, AI will become ultra-fast, high-volume streaming for low-latency.

\section{FUTURE DEVELOPMENT OF 5G}

As the world continues on into the future, $5 \mathrm{G}$ will also face its own future of issues, implementation, impacts, and development. This paper has already covered the barriers that $5 \mathrm{G}$ faces in regulation and infrastructural construction, and of course, there are a litany of logistical and theoretical concerns and problems involved in the transition from the lab to the real world for $5 \mathrm{G}$, but one area that often gets overlooked is health.

For decades, theories about radiation causing brain cancer, reduced fertility, and a variety of other health problems have been circulated in the general public, 
particularly and stereotypically by older generations. In recent times, some have even perpetuated the baseless conspiracy theory that $5 \mathrm{G}$ is linked to causing symptoms of coronavirus or transmitting it, causing the US Federal Emergency Management Agency to formally put out a statement saying unequivocally that " $5 \mathrm{G}$ technology does NOT cause coronavirus.”

Radiation is typically classified as ionizing or non-ionizing with the former being associated with shorter wavelengths/higher frequencies and being deleterious to people's health as it has the risk of breaking apart chemical bonds in DNA, causing cells to be damaged and leading to cancer in some instances as noted by the FDA.The preponderance of cellphone radiation resides in the radio frequency (RF) range: a long wavelength, lower frequency, and typically harmless form of radiation as it relates to the detrimental health effects mentioned previously. The microwave and millimeter wavelength radiation used by most $5 \mathrm{G}$ services also lie in the RF range.

However, some worry about the oxidative stress propagated by $5 \mathrm{G}$ devices and though the American Cancer Society, EPA, and National Toxicology Program all deny links between RF range radiation and tumor development, some still worry about the higher frequency bands that the FCC has auctioned off licenses for to companies like AT\&T and Verizon. ${ }^{[6]}$ The research on these bands, which are still of non-ionizing wavelengths, is still limited and many previous studies also have their own significant limitations and doubt still remains in some adamant hypochondriacs/conspiracy theorists to the point where threats have been made toward broadband engineers and of arson attacks against "cellular infrastructure in the UK.". ${ }^{[6]}$

With all this said, many still desire a for a firmer, clearer, and more definitive stance in the negation with regards to the potential health detriments of $5 \mathrm{G}$ by trusted institutions.

\section{DISCUSSION \& CONCLUSION}

Personally, I agree with the analysis that nations should be in fierce competition to develop $5 \mathrm{G}$ given the economic and geopolitical impacts and benefits afforded by monopolies on its implementation. However, at some point, we reach the necessary amount of regulation and negotiation needed to avert national security concerns and can devolve to the rest of the development and implementation to the free market. Competition will inevitably drive down costs which is good news for both consumers, companies, and potentially individual taxpayers, and the sooner we can reach that point, the sooner the world can collectively partake in the benefits of widespread $5 \mathrm{G}$ service.
Quality of life and job creation are foremost concerns of any government, and for the private sector, lucrative profits from monopolies on $5 \mathrm{G}$ services are equally enticing, but it still begs the question for many, is it not still possible to turn a reasonable profit while resorting the free market without resorting to bitter negotiations and heavy-handed public sector interference so long as we are safely above national security concerns? Of course, many will dismiss this question/hope as wishful thinking for a globalist future, and surely, no pragmatic national government will forego their shot at becoming/maintaining their status as a world superpower just for some rosy aforementioned world order, and sadly, the US and other dominant world powers will either continue down their icy path of protectionism or wholeheartedly accept Chinese technology with no security concerns and with no middle ground between the two. After all, who am I to challenge the policy experts with my limited resources, intellect, and scope?

\section{REFERENCES}

[1] Imnovation-hub,2017. What is 5G technology and what will its impact be like in our everyday life? https://www.imnovation-hub.com/society/what-is-5 $\mathrm{g} /$

[2] Consumer Technology Association, 2020. Did You Know There Are Three 5G Network Types? https://www.ces.tech/Articles/2020/October/Did-Y ou-Know-There-Are-Three-5G-Network-Types.asp $\mathrm{x}$

[3] Nippon Telegraph and Telephone Corporation, 2020.World' s First Attempt at Optical Transmission Property Control by Optimizing Optical Cable Structure. https://www.ntt.co.jp/news2020/2003e/200309a.ht $\mathrm{ml}$.

[4] Telecompetitor,2020,5G Economic Forecast: $\$ 8$ Trillion Impact on Global GDP by 2030. https://www.telecompetitor.com/5g-economic-fore cast-8-trillion-impact-on-global-gdp-by-2030/.

[5] Karen Campbell,2019.The 5G Economy, How 5G will contribute to the global economy.

[6] Marguerite Reardon,2020.Is 5G making you sick? Probably not. https://www.cnet.com/news/is-5g-making-you-sick -probably-not/ 